Moroccan J. of Pure and Appl. Anal. (MJPAA)

Volume 7(3), 2021, Pages 350-363

ISSN: Online 2351-8227 - Print 2605-6364

DOI: $10.2478 / \mathrm{mjpaa}-2021-0023$

\title{
Some fixed point theorems of rational type contraction in $b$-metric spaces
}

\author{
Merdaci Seddik ${ }^{1}$ and Hamaizia TaIeb ${ }^{2}$
}

Aвstract. In this paper, we prove some common fixed point theorems satisfying contractive type mapping in the setting of $b$-metric spaces. The presented theorem is an extension the results of M. Sarwar and M. U. Rahman [23] as well as a generalization of many well-known results in the literature through the context of b-metric spaces. Also, we present a few examples to illustrate the validity of the results obtained in the paper. Finally, results are applied to find the solution for an integral equation.

Mathematics Subject Classification (2020). 35B40, 74F05, 74F20, 93D15, 93D20.

Key words and phrases. $b$-metric spaces, Fixed points, Common fixed point, Cauchy sequence, Rational contractive condition, Nonlinear integral equations.

\section{Introduction}

S. Banach [6] proved a very important result in complete metric spaces which gives unique fixed point on complete metric space. In 1989, Bakhtin [5] and Czerwik [10] introduced the concept of $b$-metric spaces as a generalization of metric spaces. Many researchers extended and proved this principle for the study of fixed points in standard metric space or other generalized metric spaces. We refer the readers to ( M. Boriceanu [7] Bota et al. [8], Ding et al. [12], A.

Received : September 16, 2020 - Accepted : January 31, 2021.

(C) The Author(s) 2021. This article is published with open access by Sidi Mohamed Ben Abdallah University.

${ }^{1}$ Department of Mathematics, Applied Mathematics Laboratory, University of Kasdi Merbah Ouargla, Algeria, e-mail: merdaciseddik@gmail.com

${ }^{2}$ System Dynamics and Control Laboratory, Department of Mathematics and Informatics, University of Oum El Bouaghi, Algeria,

e-mail: tayeb042000@yahoo.fr (Correspondence author). 
A. Harandi [13], Mehmet Kir et al. [17], Ozturk et al. [21]. On the other hand, contractive conditions of rational type have been used for many researchers (Khan et al. [16], Sarwar and Rahman [23], S. Xie et al. [24]). In this work using the notion of $b$-metric spaces and some properties of them we prove and extend some well-known fixed point theorems which are also valid in $b$-metric spaces, this study involves rational contractive type conditions. We also present some concrete examples that show the validity of our results.

\section{Preliminaries}

Let's start this section by defining some important notations and definitions that will be used in our discussion.

Definition 2.1 ([8]). Let $X$ be a nonempty set and $s \geq 1$ be a given real number. A function $d: X \times X \rightarrow \mathbb{R}^{+}$is a b-metric on $X$ if for all $x, y, z \in X$ the following conditions hold:

(1) $d(x, y)=0$ if and only if $x=y$.

(2) $d(x, y)=d(y, x)$.

(3) $d(x, z) \leq s[d(x, y)+d(y, z)]$.

In this case, the pair $(X, d)$ is called a b-metric space.

It is clear from the notion of $b$-metric that every metric space is $b$-metric for $s=1$, but the converse is not true.

We give some well-known examples of $b$-metric spaces as following .

Example 2.1 ([14]). Let $0<p<1$ and define $L_{p}[a, b]$ by

$$
L_{p}[a, b]=\left\{\left.x(t)\left|\int_{a}^{b}\right| x(t)\right|^{p} d t<\infty\right\},
$$

where the mapping $d: L_{p}[a, b] \times L_{p}[a, b] \longrightarrow \mathbb{R}^{+}$is defined by

$$
d(x, y)=\left(\int_{a}^{b}|x(t)-y(t)|^{p}\right)^{\frac{1}{p}}
$$

for each $x=x(t), y=y(t) \in L_{p}[a, b]$. Then $\left(L_{p}[a, b], d\right)$ is a b-metric space with coefficient $s=2^{\frac{1}{p}-1}$.

Example 2.2. [15] Let $X=\mathbb{N} \cup\{\infty\}$. We define a mapping $d: X \times X \longrightarrow \mathbb{R}^{+}$as follows:

$$
d(m, n)= \begin{cases}0 & \text { if } m=n \\ \left|\frac{1}{m}-\frac{1}{n}\right| & \text { if one of } m, n \text { is even and the other is even or } \infty \\ 5 & \text { if one of } m, n \text { is odd and the other is odd or } \infty \\ 2 & \text { otherwise } m=n .\end{cases}
$$

Then $(X, d)$ is a b-metric space with coefficient $s=\frac{5}{2}$. 
Example 2.3. Let $X=\{4,5,6\}$ and $d(4,5)=d(5,4)=1, d(4,6)=d(6,4)=4, d(5,6)=$ $d(6,5)=2$, and $d(4,4)=d(5,5)=d(6,6)=0$.

and $d(x, z) \leq \frac{4}{3}[d(x, y)+d(y, z)]$ for all $x, y, z \in X$.

then $(X, d)$ is a $b$-metric space $\left(s=\frac{4}{3}\right)$ but $(X, d)$ is not a metric space because it lacks the triangular property:

$$
4=d(4,6)>d(4,5)+d(5,6)=1+2=3 .
$$

Definition $2.2([7])$. Let $(X, d)$ be a b-metric space. Then a sequence $\left\{x_{n}\right\}$ in $X$ is called:

(1) convergent if and only if there exists $u \in X$ such that $d\left(x_{n}, u\right) \rightarrow 0$, as $n \rightarrow+\infty$. In this case, we write $\lim _{n \rightarrow \infty} x_{n}=u$.

(2) Cauchy if and only if $d\left(x_{n}, x_{m}\right) \rightarrow 0$, as $n, m \rightarrow+\infty$.

Remark 2.1 ([10]). In a b-metric space $(X, d)$ the following assertions hold:

(i) a convergent sequence has a unique limit,

(ii) each convergent sequence is Cauchy,

(iii) in general, a b-metric is not continuous.

Definition 2.3 ([13]). A b-metric space $(X, d)$ is said to be complete if every Cauchy sequence in $X$ converges to a point of $X$.

\section{Mains results}

The following lemma is useful in proving all main results.

Lemma 3.1 ([15]). Let $(X, d)$ be a $b$-metric space with coefficient $s \geq 1$ and $T: X \rightarrow X$ be a mapping. Suppose that $\left\{x_{n}\right\}$ is a sequence in $X$ induced by $x_{n+1}=T x_{n}$ such that

$$
d\left(x_{n}, x_{n+1}\right) \leq \lambda d\left(x_{n-1}, x_{n}\right),
$$

for all $n \in \mathbb{N}$, where $\lambda \in[0,1)$ is a constant. Then $\left\{x_{n}\right\}$ is a Cauchy sequence.

Now, we are ready to prove our main theorems.

Theorem 3.1. Let $(X, d)$ be a complete b-metric space with a coefficient $s \geq 1$, and $T, S: X \rightarrow X$ be two mappings on $X$ satisfying the condition

$$
d(T x, S y) \leq a_{1} d(x, y)+a_{2} \frac{d(x, T x) d(x, S y)+d(y, S y) d(y, T x)}{d(x, S y)+d(y, T x)},
$$

for all, $x, y$ in $X$ and $a_{1}, a_{2} \geq 0, d(x, S y)+d(y, T x) \neq 0$ with $a_{1}+a_{2}<1$. Then $T$ and $S$ have $a$ unique common fixed point. 
Proof. For any arbitrary point, $x_{0} \in X$. Define sequence $\left\{x_{n}\right\}$ in $X$ such that

$$
x_{2 n+1}=T x_{2 n}, \quad x_{2 n+2}=S x_{2 n+1}, \quad \text { for all } n \in \mathbb{N} .
$$

Suppose that there is some $n \in \mathbb{N}$ such that $x_{n}=x_{n+1}$. If $n=2 k$, then $x_{2 k}=x_{2 k+1}$ and from the condition (3.2) with $x=x_{2 k}$ and $y=x_{2 k+1}$ we have

$$
\begin{aligned}
& d\left(x_{2 k+1}, x_{2 k+2}\right)=d\left(T x_{2 k}, S x_{2 k+1}\right) \\
& \leq a_{1} d\left(x_{2 k}, x_{2 k+1}\right)+a_{2} \frac{d\left(x_{2 k}, T x_{2 k}\right) d\left(x_{2 k}, S x_{2 k+1}\right)+d\left(x_{2 k+1}, S x_{2 k+1}\right) d\left(x_{2 k+1}, T x_{2 k}\right)}{d\left(x_{2 k}, S x_{2 k+1}\right)+d\left(x_{2 k+1}, T x_{2 k}\right)} \\
& =a_{1} d\left(x_{2 k}, x_{2 k+1}\right)+a_{2} \frac{d\left(x_{2 k}, x_{2 k+1}\right) d\left(x_{2 k}, x_{2 k+2}\right)+d\left(x_{2 k+1}, x_{2 k+2}\right) d\left(x_{2 k+1}, x_{2 k+1}\right)}{d\left(x_{2 k}, x_{2 k+2}\right)+d\left(x_{2 k+1}, x_{2 k+1}\right)} \\
& =0 .
\end{aligned}
$$

We have $d\left(x_{2 k+1}, x_{2 k+2}\right)=0$. Hence $x_{2 k+1}=x_{2 k+2}$. Thus we have $x_{2 k}=x_{2 k+1}=x_{2 k+2}$. By (3.3), it means $x_{2 k}=T x_{2 k}=S x_{2 k}$, that is, $x_{2 k}$ is a common fixed point of $T$ and $S$.

If $n=2 k+1$, then using the same arguments as in the case $x_{2 k}=x_{2 k+1}$, it can be shown that $x_{2 k+1}$ is a common fixed point of $T$ and $S$.

From now on, we suppose that $x_{n} \neq x_{n+1}$ for all $n \in \mathbb{N}$.

Step 1: We will show that

$$
d\left(x_{n}, x_{n+1}\right) \leq\left(a_{1}+a_{2}\right) d\left(x_{n-1}, x_{n}\right), \quad \text { for all } n \in \mathbb{N} .
$$

There are two cases which we have to consider.

Case 1. $n=2 k+1, \quad k \in \mathbb{N}$.

From the condition (3.2) with $x=x_{2 k}$ and $y=x_{2 k+1}$ we have

$$
\begin{aligned}
& d\left(x_{2 k+1}, x_{2 k+2}\right)=d\left(T x_{2 k}, S x_{2 k+1}\right) \\
& \leq a_{1} d\left(x_{2 k}, x_{2 k+1}\right)+a_{2} \frac{d\left(x_{2 k}, T x_{2 k}\right) d\left(x_{2 k}, S x_{2 k+1}\right)+d\left(x_{2 k+1}, S x_{2 k+1}\right) d\left(x_{2 k+1}, T x_{2 k}\right)}{d\left(x_{2 k}, S x_{2 k+1}\right)+d\left(x_{2 k+1}, T x_{2 k}\right)} \\
& \leq a_{1} \cdot d\left(x_{2 k}, x_{2 k+1}\right)+a_{2} \frac{d\left(x_{2 k}, x_{2 k+1}\right) d\left(x_{2 k}, x_{2 k+2}\right)+d\left(x_{2 k+1}, x_{2 k+2}\right) d\left(x_{2 k+1}, x_{2 k+1}\right)}{d\left(x_{2 k}, x_{2 k+2}\right)+d\left(x_{2 k+1}, x_{2 k+1}\right)} \\
& =a_{1} d\left(x_{2 k}, x_{2 k+1}\right)+a_{2} \frac{d\left(x_{2 k}, x_{2 k+1}\right) d\left(x_{2 k}, x_{2 k+2}\right)}{d\left(x_{2 k}, x_{2 k+2}\right)} \\
& =\left(a_{1}+a_{2}\right) d\left(x_{2 k}, x_{2 k+1}\right) .
\end{aligned}
$$

Thus we obtain that

$$
d\left(x_{n}, x_{n+1}\right) \leq\left(a_{1}+a_{2}\right) d\left(x_{n-1}, x_{n}\right), \quad n=2 k, \quad k \in \mathbb{N} .
$$

Case 2. $n=2 k, \quad k \in \mathbb{N}$. By using the same argument as in Case 1, it can be proved that (3.4) holds for $n=2 k$, that is

$$
d\left(x_{n}, x_{n+1}\right) \leq\left(a_{1}+a_{2}\right) d\left(x_{n-1}, x_{n}\right), \quad n=2 k+1, \quad k \in \mathbb{N} .
$$

From (3.5) and (3.6) we can conclude that

$$
d\left(x_{n}, x_{n+1}\right) \leq\left(a_{1}+a_{2}\right) d\left(x_{n-1}, x_{n}\right), \quad \text { for all } n \in \mathbb{N} .
$$


Thus we obtain that (3.4) holds.

Since $a_{1}+a_{2}<1$, by Lemma 3.1 we can say that $\left\{x_{n}\right\}$ is a Cauchy sequence in $(X, d)$. Since $(X, d)$ is a complete $b$-metric space, $\left\{x_{n}\right\}$ converges to some $u \in X$ as $n \longrightarrow+\infty$.

Step 2: We will prove that $T u=S u=u$.

Using the triangular inequality and (3.2), we have

$$
\begin{aligned}
d(u, T u) \leq & s\left[d\left(u, x_{2 n+2}\right)+d\left(x_{2 n+2}, T u\right)\right] \\
= & s d\left(u, x_{2 n+2}\right)+s d\left(T u, S x_{2 n+1}\right) \\
\leq & s d\left(u, x_{2 n+2}\right)+s a_{1} d\left(u, x_{2 n+2}\right) \\
& +s a_{2} \frac{d(u, T u) d\left(u, S x_{2 n+1}\right)+d\left(x_{2 n+1}, S x_{2 k+1}\right) d\left(x_{2 n+1}, T u\right)}{d\left(u, S x_{2 n+1}\right)+d\left(x_{2 n+1}, T u\right)} \\
= & s d\left(u, x_{2 n+2}\right)+s a_{1} d\left(u, x_{2 n+2}\right) \\
& +s a_{2} \frac{d(u, T u) d\left(u, x_{2 n+2}\right)+d\left(x_{2 n+1}, x_{2 n+2}\right) d\left(x_{2 n+1}, T u\right)}{d\left(u, x_{2 n+2}\right)+d\left(x_{2 n+1}, T u\right)}
\end{aligned}
$$

Taking the limit as $n \rightarrow+\infty$, we obtain that

$d(u, T u) \leq 0$, hence $d(u, T u)=0 \Longrightarrow T u=u$.

Similarly, we obtain $S u=u$, thus $u$ is a common fixed point of $T$ and $S$.

Step 3: We will prove that $T$ and $S$ have a unique common fixed point.

Suppose now that $u$ and $v$ are different common fixed points of $T$ and $S$, then from (3.2), we have

$$
\begin{aligned}
d(u, v) & =d(T u, S v) \\
& \leq a_{1} d(u, v)+a_{2} \frac{d(u, T u) \cdot d(u, S v)+d(v, S v) d(v, T u)}{d(u, S v)+d(v, T u)} \\
& =a_{1} d(u, v) .
\end{aligned}
$$

Since $a_{1}<1$, we have $d(u, v)=0$.

Thus, we proved that $T$ and $S$ have a unique common fixed point in $X$.

Our second result is the following.

Theorem 3.2. Let $(X, d)$ be a complete b-metric space with a coefficient $s \geq 1$, and $T, S: X \rightarrow X$ be two mappings on $X$ satisfying the condition

$$
\begin{aligned}
d(T x, S y) \leq & a_{1} d(x, y)+a_{2} \frac{d(y, S y)[1+d(x, T x)]}{1+d(x, y)} \\
& +a_{3} \frac{d(y, S y)+d(y, T x)}{1+d(y, S y) d(y, T x)}
\end{aligned}
$$

for all, $x, y \in X$, where $a_{1}, a_{2}, a_{3} \geq 0$, and $s\left(a_{1}+a_{2}+a_{3}\right)<1$. Then $T$ and $S$ have a unique common fixed point.

Proof. Let $x_{0}$ be arbitrary in $X$, we define a sequence $\left\{x_{n}\right\}$ in $X$ such that

$$
x_{2 n+1}=T x_{2 n}, \quad x_{2 n+2}=S x_{2 n+1}, \quad \text { for all } n \in \mathbb{N} \text {. }
$$


Suppose that there is some $n \in \mathbb{N}$ such that $x_{n}=x_{n+1}$. If $n=2 k$, then $x_{2 k}=x_{2 k+1}$ and from the condition (3.8) with $x=x_{2 k}$ and $y=x_{2 k+1}$ we have

$$
\begin{aligned}
d\left(x_{2 k+1}, x_{2 k+2}\right)= & d\left(T x_{2 k}, S x_{2 k+1}\right) \\
\leq & a_{1} d\left(x_{2 k}, x_{2 k+1}\right)+a_{2} \frac{d\left(x_{2 k+1}, S x_{2 k+1}\right)\left[1+d\left(x_{2 k}, T x_{2 k}\right)\right]}{1+d\left(x_{2 k}, x_{2 k+1}\right)} \\
& +a_{3} \frac{d\left(x_{2 k+1}, S x_{2 k+1}\right)+d\left(x_{2 k+1}, T x_{2 k}\right)}{1+d\left(x_{2 k+1}, S x_{2 k+1}\right) d\left(x_{2 k+1}, T x_{2 k}\right)} \\
= & a_{1} d\left(x_{2 k}, x_{2 k+1}\right)+a_{2} \frac{d\left(x_{2 k+1}, x_{2 k+2}\right)\left[1+d\left(x_{2 k}, x_{2 k+1}\right)\right]}{1+d\left(x_{2 k}, x_{2 k+1}\right)} \\
& +a_{3} \frac{d\left(x_{2 k+1}, x_{2 k+2}\right)+d\left(x_{2 k+1}, x_{2 k+1}\right)}{1+d\left(x_{2 k+1}, x_{2 k+2}\right) d\left(x_{2 k+1}, x_{2 k+1}\right)}
\end{aligned}
$$

then

$$
\left(1-a_{3}\right) d\left(x_{2 k+1}, x_{2 k+2}\right) \leq 0 .
$$

Since $0 \leq a_{3}<1$, we have $d\left(x_{2 k+1}, x_{2 k+2}\right)=0$. Hence $x_{2 k+1}=x_{2 k+2}$. Thus we have $x_{2 k}=$ $x_{2 k+1}=x_{2 k+2}$. By (3.9), it means $x_{2 k}=T x_{2 k}=S x_{2 k}$, that is, $x_{2 k}$ is a common fixed point of $T$ and $S$.

If $n=2 k+1$, then using the same arguments as in the case $x_{2 k}=x_{2 k+1}$, it can be shown that $x_{2 k+1}$ is a common fixed point of $T$ and $S$.

From now on, we suppose that $x_{n} \neq x_{n+1}$ for all $n \in \mathbb{N}$.

Step 1: We will show that

$$
d\left(x_{n}, x_{n+1}\right) \leq \frac{a_{1}}{1-\left(a_{2}+a_{3}\right)} d\left(x_{n-1}, x_{n}\right), \quad \text { for all } n \in \mathbb{N} .
$$

There are two cases which we have to consider.

Case 1. $n=2 k+1, \quad k \in \mathbb{N}$.

From the condition (3.8) with $x=x_{2 k}$ and $y=x_{2 k+1}$ we have

$$
\begin{aligned}
d\left(x_{2 k+1}, x_{2 k+2}\right)= & d\left(T x_{2 k}, S x_{2 k+1}\right) \\
\leq & a_{1} d\left(x_{2 k}, x_{2 k+1}\right)+a_{2} \frac{d\left(x_{2 k+1}, S x_{2 k+1}\right)\left[1+d\left(x_{2 k}, T x_{2 k}\right)\right]}{1+d\left(x_{2 k}, x_{2 k+1}\right)} \\
& +a_{3} \frac{d\left(x_{2 k+1}, S x_{2 k+1}\right)+d\left(x_{2 k+1}, T x_{2 k}\right)}{1+d\left(x_{2 k+1}, S x_{2 k+1}\right) \cdot d\left(x_{2 k+1}, T x_{2 k}\right)} \\
= & a_{1} d\left(x_{2 k}, x_{2 k+1}\right)+a_{2} \frac{d\left(x_{2 k+1}, x_{2 k+2}\right)\left[1+d\left(x_{2 k}, x_{2 k+1}\right)\right]}{1+d\left(x_{2 k}, x_{2 k+1}\right)} \\
& +a_{3} \frac{d\left(x_{2 k+1}, x_{2 k+2}\right)+d\left(x_{2 k+1}, x_{2 k+1}\right)}{1+d\left(x_{2 k+1}, x_{2 k+2}\right) d\left(x_{2 k+1}, x_{2 k+1}\right)} \\
= & \frac{a_{1}}{1-\left(a_{2}+a_{3}\right)} d\left(x_{2 k}, x_{2 k+1}\right) .
\end{aligned}
$$


Thus we obtain that

$$
d\left(x_{n}, x_{n+1}\right) \leq \frac{a_{1}}{1-\left(a_{2}+a_{3}\right)} d\left(x_{n-1}, x_{n}\right), \quad n=2 k, \quad k \in \mathbb{N} .
$$

Case 2. $n=2 k, \quad k \in \mathbb{N}$. By using the same argument as in Case 1, it can be proved that (3.10) holds for $n=2 k$, that is

$$
d\left(x_{n}, x_{n+1}\right) \leq \frac{a_{1}}{1-\left(a_{2}+a_{3}\right)} d\left(x_{n-1}, x_{n}\right), \quad n=2 k+1, \quad k \in \mathbb{N} .
$$

From (3.11) and (3.12) we can conclude that

$$
d\left(x_{n}, x_{n+1}\right) \leq \frac{a_{1}}{1-\left(a_{2}+a_{3}\right)} d\left(x_{n-1}, x_{n}\right), \quad \text { for all } n \in \mathbb{N},
$$

where $h=\frac{a_{1}}{1-\left(a_{2}+a_{3}\right)}$ with $h<\frac{1}{s} \leq 1$, because $s\left(a_{1}+a_{2}+a_{3}\right)<1$.

Thus we proved that (3.10) holds.

Now from Lemma 3.1 we can say that $\left\{x_{n}\right\}$ is a Cauchy sequence in $(X, d)$. Since $(X, d)$ is a complete $b$-metric space, $\left\{x_{n}\right\}$ converges to some $u \in X$ as $n \longrightarrow+\infty$.

Step 2: We will prove that $T u=S u=u$.

By using the triangular inequality and (3.8), we have

$$
\begin{aligned}
d(u, T u) \leq & s\left[d\left(u, x_{2 n+2}\right)+d\left(x_{2 n+2}, T u\right)\right] \\
= & s d\left(u, x_{2 n+2}\right)+s d\left(T u, S x_{2 n+1}\right) \\
\leq & s d\left(u, x_{2 n+2}\right)+s a_{1} d\left(u, x_{2 n+1}\right)+s a_{2} \frac{d\left(x_{2 n+1}, S x_{2 n+1}\right)[1+d(u, T u)]}{1+d\left(u, x_{2 n+1}\right)} \\
& \quad+s a_{3} \frac{d\left(x_{2 n+1}, S x_{2 n+1}\right)+d\left(x_{2 n+1}, T u\right)}{1+d\left(x_{2 n+1}, S x_{2 n+1}\right) d\left(x_{2 n+1}, T u\right)} .
\end{aligned}
$$

Taking the limit as $n \rightarrow+\infty$, we obtain that

$$
d(u, T u) \leq s a_{3} d(u, T u) .
$$

Since $s a_{3}<1$, hence $d(u, T u)=0$, thus $T u=u$.

Similarly, we obtain

$$
d(u, S u) \leq s\left(a_{2}+a_{3}\right) d(u, S u) .
$$

Since $s\left(a_{2}+a_{3}\right)<1, d(u, S u)=0$, thus $S u=u$.

Thus $u$ is a common fixed piont of $T$ and $S$.

Step 3: We will prove that $T$ and $S$ have a unique common fixed point.

Suppose now that $u$ and $v$ are different common fixed points of $T$ and $S$, then from (3.8), we have

$$
\begin{aligned}
d(u, v) & =d(T u, S v) \\
& \leq a_{1} d(u, v)+a_{2} \frac{d(v, S v)[1+d(u, T u)]}{1+d(u, v)}+a_{3} \frac{d(v, S v)+d(v, T u)}{1+d(v, S v) d(v, T u)} \\
& =\left(a_{1}+a_{3}\right) d(u, v) .
\end{aligned}
$$


Since $0<a_{1}+a_{3}<1$, we have $d(u, v)=0$.

Thus, we proved that $T$ and $S$ have a unique common fixed point in $X$.

The third and final result is the following.

Theorem 3.3. Let $(X, d)$ be a complete b-metric space with a constant $s \geq 1$ and $f: X \rightarrow X$ be $a$ mapping on X. Suppose that $a_{1}, a_{2}, a_{3}$ are nonnegative reals with $a_{1}+a_{3}<1, \frac{a_{1}+a_{2}}{s-a_{3}}<1$ such that the inequality

$$
s d(f x, f y) \leq a_{1} d(x, y)+a_{2} \frac{d(x, f x) d(y, f y)}{1+d(f x, f y)}+a_{3} d(f x, f y),
$$

holds for each $x, y \in X$. Then $f$ has a unique fixed point.

Proof. Let $x_{0}$ be arbitrary in $X$, we define a sequence $\left\{x_{n}\right\}$ in $X$ such that

$$
x_{n+1}=f x_{n}, \quad \text { for all } n \in \mathbb{N} .
$$

From the condition (3.14) with $x=x_{n}$ and $y=x_{n-1}$, Therefore

$$
\begin{aligned}
s d\left(x_{n+1}, x_{n}\right) & =s d\left(f x_{n}, f x_{n-1}\right) \\
& \leq a_{1} d\left(x_{n}, x_{n-1}\right)+a_{2} \frac{d\left(x_{n}, f x_{n}\right) d\left(x_{n-1}, f x_{n-1}\right)}{1+d\left(f x_{n}, f x_{n-1}\right)}+a_{3} d\left(f x_{n}, f x_{n-1}\right) \\
& =a_{1} d\left(x_{n}, x_{n-1}\right)+a_{2} \frac{d\left(x_{n}, x_{n+1}\right) d\left(x_{n-1}, x_{n}\right)}{1+d\left(x_{n+1}, x_{n}\right)}+a_{3} d\left(x_{n+1}, x_{n}\right) \\
& \leq a_{1} d\left(x_{n}, x_{n-1}\right)+a_{2} \frac{d\left(x_{n}, x_{n+1}\right) d\left(x_{n-1}, x_{n}\right)}{d\left(x_{n+1}, x_{n}\right)}+a_{3} d\left(x_{n+1}, x_{n}\right)
\end{aligned}
$$

then

$$
d\left(x_{n+1}, x_{n}\right) \leq \frac{\left(a_{1}+a_{2}\right)}{s-a_{3}} d\left(x_{n-1}, x_{n}\right) .
$$

Now from Lemma 3.1 we can say that $\left\{x_{n}\right\}$ is a Cauchy sequence in $(X, d)$. Since $(X, d)$ is a complete $b$-metric space, then $\left\{x_{n}\right\}$ converges to some $u \in X$ as $n \longrightarrow+\infty$.

We will prove that $f u=u$.

Again by triangle inequality and (3.14), we have

$$
\begin{aligned}
d(u, f u) & \leq s\left[d\left(u, x_{n+1}\right)+d\left(x_{n+1}, f u\right)\right] \\
& =s\left[d\left(u, x_{n+1}\right)+d\left(f u, f x_{n}\right)\right] \\
& \leq s d\left(u, x_{n+1}\right)+a_{1} d\left(u, x_{n}\right)+a_{2} \frac{d\left(x_{n}, f x_{n}\right) d(u, f u)}{1+d\left(f x_{n}, f u\right)}+a_{3} d\left(f u, f x_{n}\right) .
\end{aligned}
$$

Taking the limit as $n \longrightarrow+\infty$, we obtain that

$$
\left(1-a_{3}\right) d(u, f u) \leq 0,
$$

since $0<a_{3}<1$, then

$$
d(u, f u) \leq 0
$$


which is a contradiction, so $d(u, f u)=0$. Hence, $f u=u$, thus $u$ is fixed point of $f$. We will prove that $f$ have a unique fixed point.

Suppose now that $u$ and $v$ are different fixed points of $f$, then from (3.14), it follows that

$$
\begin{aligned}
s d(u, v)=s d(f u, f v) & \leq a_{1} d(u, v)+a_{2} \frac{d(u, f u) d(v, f v)}{1+d(f u, f v)}+a_{3} d(f u, f v) \\
& =a_{1} d(u, v)+a_{2} \frac{d(u, u) d(v, v)}{1+d(u, v)}+a_{3} d(u, v) \\
& =\left(a_{1}+a_{3}\right) d(u, v) .
\end{aligned}
$$

Since $a_{1}+a_{3}$ is nonnegative reals with $a_{1}+a_{3}<1$, then we have $d(u, v)=0$. Thus, we proved that $f$ have a unique fixed point in $X$.

Remark 3.1. By choosing:

$T=S$ in Theorem 3.1, we get Theorem (3.2) of [23].

$T=S$ in Theorem 3.2, we deduce Theorem (3.3) of [23].

$T=S, a_{2}=0$ and $s=1$, in Theorem 3.1 is the result of $S$. Banach [6].

$T=S, a_{3}=0$ and $s=1$, in Theorem 3.2 is the result of B. K. Dass and S. Gupta [11].

Now, we give some examples to support our results.

Example 3.1. Let $X=\left\{0, \frac{1}{2}, \frac{3}{2}\right\}$, and let $d: X \times X \rightarrow[0,+\infty)$ be a mapping satisfies the following condition for all $x, y \in X$ :

(1) $d(x, y)=0$, where $x=y$.

(2) $d\left(0, \frac{1}{2}\right)=d\left(\frac{1}{2}, 0\right)=\frac{1}{4}, \quad d\left(0, \frac{3}{2}\right)=d\left(\frac{3}{2}, 0\right)=\frac{1}{8}, \quad d\left(\frac{1}{2}, \frac{3}{2}\right)=d\left(\frac{3}{2}, \frac{1}{2}\right)=\frac{1}{2}$.

Then,$(X, d)$ is a complete $b$-metric space with coefficient $s=\frac{4}{3}>1$. Consider mappings $T, S: X \rightarrow X$, define by

$$
\begin{aligned}
& T(0)=0, T\left(\frac{1}{2}\right)=0, T\left(\frac{3}{2}\right)=0, \\
& S(0)=0, S\left(\frac{1}{2}\right)=\frac{3}{2}, S\left(\frac{3}{2}\right)=0 .
\end{aligned}
$$

Let $a_{1}=\frac{1}{2}, a_{2}=\frac{1}{4}$ and $a_{3}=\frac{1}{8}$, clearly, $a_{1}+a_{2}+a_{3}<1$. Next, we will verify the condition (3.8). It have the following cases to be considered.

Case 1. $d(T x, S y)=0$, the inequality (3.8) holds.

Case 2. $d(T x, S y) \neq 0$, we have the following three cases to be considered.

Case 2.1. $x=0, y=\frac{1}{2}$, we can get $d(T x, S y)=\frac{1}{8}$, then

$$
\begin{aligned}
\frac{1}{8} \leq & \frac{1}{2} \times \frac{1}{4}+\frac{1}{4} \times \frac{2}{5}+\frac{1}{8} \times \frac{2}{3} \\
= & a_{1} d(x, y)+a_{2} \frac{d(y, S y)[1+d(x, T x)]}{1+d(x, y)} \\
& +a_{3} \frac{d(y, S y)+d(y, T x)}{1+d(y, S y) d(y, T x)}
\end{aligned}
$$


therefore, the inequality (3.8) holds.

Case 2.2. $x=\frac{1}{2}, y=\frac{1}{2}$, we can $\operatorname{get} d(T x, S y)=\frac{1}{8}$, then

$$
\begin{aligned}
\frac{1}{8} \leq & \frac{1}{2} \times 0+\frac{1}{4} \times \frac{5}{8}+\frac{1}{8} \times \frac{2}{3} \\
= & a_{1} d(x, y)+a_{2} \frac{d(y, S y)[1+d(x, T x)]}{1+d(x, y)} \\
& +a_{3} \frac{d(y, S y)+d(y, T x)}{1+d(y, S y) d(y, T x)}
\end{aligned}
$$

then, the inequality (3.8) holds.

Case 2.3. $x=\frac{3}{2}, y=\frac{1}{2}$, we can $g e t d(T x, S y)=\frac{1}{8}$, then

$$
\begin{aligned}
\frac{1}{8} \leq & \frac{1}{2} \times \frac{1}{2}+\frac{1}{4} \times \frac{3}{8}+\frac{1}{8} \times \frac{2}{3} \\
= & a_{1} d(x, y)+a_{2} \frac{d(y, S y)[1+d(x, T x)]}{1+d(x, y)} \\
& +a_{3} \frac{d(y, S y)+d(y, T x)}{1+d(y, S y) d(y, T x)}
\end{aligned}
$$

subsequently, the inequality (3.8) holds.

Therefore, we showed that the condition (3.8) is satisfied in all cases. Then $T$ and $S$ have a unique common fixed point $x=0$.

Example 3.2. Let $X=[0,1]$ be equipped with the b-metric $d(x, y)=|x-y|^{2}$ for all $x, y \in X$. Then $(X, d)$ is a b-metric space with parameter $s=2$ and it is complete.

Let $f: X \longrightarrow X$ be defined as

$$
f(x)=\frac{x}{3}, \quad x \in[0,1]
$$

Then for $x, y \in X$,

$$
\begin{aligned}
2 d(f x, f y) & =2 d\left(\frac{x}{3}, \frac{y}{3}\right) \\
& =\frac{2}{9}|x-y|^{2} \\
& \leq \frac{2}{9} d(x, y)+\frac{4}{9} \frac{d(x, f x) d(y, f y)}{1+d(f x, f y)}+\frac{2}{3} d(f x, f y) .
\end{aligned}
$$

Clearly, $a_{1}+a_{3}=\frac{2}{9}+\frac{2}{3}=\frac{8}{9}<1$ and $a_{1}+a_{2}+a_{3}=\frac{12}{9}<2=s$.

We conclude that inequality (3.14) remains valid by an application of theorem $3.3, f$ has a unique fixed point. It is seen that 0 is the unique fixed point of $f$. 


\section{Application to nonlinear integral equations}

The solutions of integral equations have a major role in the fields of science and engineering, therefore, many applications and methods have been developed for solving some of them (see [9], [18], [19]).

Let $X=C[a, b]$ be a set of all real valued continuous functions on $[a, b]$, where $[a, b]$ is a closed and bounded interval in $\mathbb{R}$. For $p>1$ a real number, define $d: X \times X \rightarrow \mathbb{R}_{+}$by:

$$
d(x, y)=\max _{t \in[a, b]}|x(t)-y(t)|^{p}
$$

for all $x, y \in X$. Therefore, $\left(X, d, s=2^{p-1}\right)$ is a complete $b$-metric space. In this section, we apply theorem (3.3) to establish the existence uniqueness of solution of nonlinear integral equation of Fredholm type defined by:

$$
x(t)=g(t)+\lambda \int_{a}^{b} K(t, \tau, x) d \tau,
$$

where $x \in C[a, b]$ is the unknown function, $\lambda \in \mathbb{R}, t, \tau \in[a, b], K:[a, b] \times[a, b] \times \mathbb{R} \rightarrow \mathbb{R}$ and $g:[a, b] \rightarrow \mathbb{R}$ are given continuous functions.

Theorem 4.1. We will assume the following:

(i) There exists a continuous function $\psi:[a, b] \times[a, b] \rightarrow \mathbb{R}_{+}$such that for all $x, y \in X, \lambda \in \mathbb{R}$ and $t, \tau \in[a, b]$, we get

$$
|K(t, \tau, x)-K(t, \tau, y)|^{p} \leq \psi(t, \tau) M(x, y),
$$

where

$$
M(x, y)=a_{1} d(x, y)+a_{2} \frac{d(x, f x) d(y, f y)}{1+d(f x, f y)}+a_{3} d(f x, f y) .
$$

(ii) $|\lambda| \leq 1$,

(iii)

$$
\max _{t \in[a, b]} \int_{a}^{b} \psi(t, \tau) d \tau \leq \frac{1}{s(b-a)^{p-1}} .
$$

Then, the integral equation (4.1) has a solution $z \in C[a, b]$.

Proof. Define a mapping $f: X \rightarrow X$ by:

$$
f x(t)=g(t)+\lambda \int_{a}^{b} K(t, \tau, x) d \tau,
$$

for all $t \in[a, b]$. So, the existence of a solution of (4.1) is equivalent to the existence and uniqueness of fixed point of $f$. Let $q \in \mathbb{R}$ such that $\frac{1}{p}+\frac{1}{q}=1$. 
Using the Hölder inequality, (i), (ii) and (iii), we have

$$
\begin{aligned}
d(f x, f y) & =\max _{t \in[a, b]}|f x(t)-f y(t)|^{p} \\
& \leq|\lambda|^{p} \max _{t \in[a, b]}\left(\int_{a}^{b}|(K(t, \tau, x)-K(t, \tau, y))| d \tau\right)^{p} \\
& \leq \max _{t \in[a, b]}\left[\left(\int_{a}^{b} 1^{q} d \tau\right)^{\frac{1}{q}}\left(\int_{a}^{b}|(K(t, \tau, x)-K(t, \tau, y))|^{p} d \tau\right)^{\frac{1}{p}}\right]^{p} \\
& \leq(b-a)^{\frac{p}{q}} \max _{t \in[a, b]}\left(\int_{a}^{b}|(K(t, \tau, x)-K(t, \tau, y))|^{p} d \tau\right) \\
& \leq(b-a)^{p-1} \max _{t \in[a, b]}\left(\int_{a}^{b} \psi(t, \tau) d \tau M(x, y)\right) \\
& \leq(b-a)^{p-1} \max _{t \in[a, b]}\left(\int_{a}^{b} \psi(t, \tau) d \tau\right) M(x, y) \\
& \leq \frac{1}{s} M(x, y) .
\end{aligned}
$$

Thus

$$
s d(f x, f y) \leq a_{1} d(x, y)+a_{2} \frac{d(x, f x) d(y, f y)}{1+d(f x, f y)}+a_{3} d(f x, f y)
$$

Hence, all the conditions of theorem 3.3 hold. Consequently, the integral equation (4.1) has a solution $z \in C[a, b]$.

Example 4.1. Let $X=C[0,1]$ be a set of all real valued continuous functions on $[0,1]$. Define $d: X \times X \rightarrow \mathbb{R}_{+}$by:

$$
d(x, y)=\max _{t \in[0,1]}|x(t)-y(t)|^{2},
$$

for all $x, y \in X$. Therefore, $(X, d, s=2)$ is a complete b-metric space.

Consider the following problem:

$$
x(t)=\exp (t)+\frac{\pi}{4} \int_{0}^{1} \frac{t}{2} \tau x d \tau .
$$

Firstly, it can be easily checked that

$$
x(t)=\exp (t)+\frac{3 \pi}{24-\pi} t
$$


is the exact solution of (4.2).

Customize $K(t, \tau, x)=\frac{t}{2} \tau x, g(t)=\exp (t)$ and $\lambda=\frac{\pi}{4}$ in Theorem 4.1. Not that:

(1) $K$ and $g$ are continuous functions.

(2) $|\lambda|=\left|\frac{\pi}{4}\right|<1$.

(3) $\psi(t, \tau)=(t \tau)^{2}$, then

$$
\max _{t \in[0,1]} \int_{0}^{1} \psi(t, \tau) d \tau=\max _{t \in[0,1]} \int_{0}^{1}(t \tau)^{2} d \tau=\frac{1}{3} \max _{t \in[0,1]} t \leq \frac{1}{3}<\frac{1}{2}=\frac{1}{s} .
$$

(4) For $\tau \in[0,1]$, we have

$$
\begin{aligned}
|K(t, \tau, x)-K(t, \tau, y)|^{2} & =\frac{1}{4}(t \tau)^{2}|x-y|^{2} \\
& \leq \frac{1}{4}(t \tau)^{2} \max _{t \in[0,1]}|x-y|^{2} \\
& =\frac{1}{4} \psi(t, \tau) d(x, y),
\end{aligned}
$$

with $\psi(t, \tau)=(t \tau)^{2}$ and $M(x, y)=a_{1} d(x, y)+a_{2} \frac{d(x, f x) d(y, f y)}{1+d(f x, f y)}+a_{3} d(f x, f y)$, where $a_{1}=$ $\frac{1}{4}, a_{2}=a_{3}=0$, it means that $\frac{a_{1}+a_{2}}{2-a_{3}}<1$.

Therefore, the conditions of Theorem 4.1 are justified, hence the mapping $f$ has a unique fixed point in $C[0,1]$, with is the unique solution of problem (4.2).

\section{References}

[1] H. Aydi, $\alpha$-implicit contractive pair of mappings on quasi $b$-metric spaces and an application to integral equations, J. Nonlinear Convex Anal, 17, (2016), 2417-2433.

[2] H. Aydi, R. Banković, I. Mitrović, M. Nazam, Nemytzki-Edelstein-Meir-Keeler type results in $b$-metric spaces, Discrete Dynamics in Nature and Society, 2018, Article ID 4745764, (2018), 7 pages.

[3] H. Aydi, M.F. Bota, E. Karapinar, S. Mitrović, A fixed point theorem for set-valued quasi-contractions in $b$-metric spaces, Fixed Point Theory Appl, 2012, (88), (2012), 8 pages.

[4] H. Aydi, M.F. Bota, E. Karapinar, S. Moradi, A common fixed point for weak $\phi$-contractions on $b$-metric spaces, Fixed Point Theory, 13, (2), (2012), 337-346.

[5] I.A. Bakhtin, The contraction mapping principle in quasimetric spaces, (Russian), Func. An. Gos. Ped. Inst. Unianowsk, 30, (1989), 26-37.

[6] S. Banach, Sur les operations dans les ensembles abstraits et leur application aux équations int égrales, Fundam. Math, (3), (1922), 133-181.

[7] M. Boriceanu, Fixed point theory for multivalued generalized contraction on a set with two $b$-metric, studia, univ Babes, Bolya: Math, Liv(s), ( 2009 ), 1-14 .

[8] M. Bota, A. Molnar, C. Varga, On ekeland's variational principle in $b$-metric spaces, Fixed Point Theory, 12, 2, (2011), 21-28.

[9] H. Budak, Opial type inequalities for double Riemann-Stieltjes integrals, Moroccan J. of Pure and Appl. Anal, 4, (2), 2018, 111-121. 
[10] S. Czerwik, Contraction moppings in $b$-metric apaces, Acta Mathematica et Informatica Universitatis Ostraviensis, 1, (1), (1993), 5-11.

[11] B. K. Dass, S. Gupta, An extension of Banach contraction principle through rational expression, Indian J. Pure Appl. Math, (6), (1975), 1455-1458.

[12] H-S. Ding, M. Imdad, S. Radenović, J. Vujaković, On some fixed point results in $b$-metric, rectangular and b-rectangular metric spaces, Arab JN Math Sci, (22), (2016), 151-164.

[13] A. A. Harandi, Fixed point theorem for quasi-contraction mopa in $b$-metric spaces, Fixed Point Theory, 15, (2), ( 2014$), 351-358$.

[14] H. Huang, G. Deng, S. Radenović, Fixed point theorems for $C$-class functions in $b$-metric spaces and applications, J. Nonlinear Sci. Appl, (10), (2017), 5853-5868.

[15] H. Huang, G. Deng, S. Radenović, Fixed point theorems in $b$-metric spaces with applications to differential equations, Fixed Point Theory Appl, (2018), 24 pages.

[16] M. S. Khan, On a Fixed Point Theorem with PPF Dependence in the Razumikhin Class, Gazi University Journal of Science, 28, (2), (2015), 211-219.

[17] K. Mehmet, K. Hukmi, On some well known fixed point theorems in $b$-metric space, Turkish journal of analysis and number theory, 1, (1), (2013), 13-16.

[18] F. Mirzaee, Solving a class of nonlinear two-dimensional Volterra integral equations by using twodimensional triangular orthogonal functions, Journal of Mathematical Modeling, 1, (1), 2013, 28-40.

[19] F. Mirzaee, Numerical solution of system of linear integral equations via improvement of block-pulse functions, Journal of Mathematical Modeling, 4, (2), 2016, 133-159.

[20] P. K. Mishra, S. Sachdeva, S. K. Banerjee, Some Fixed Point Theorems in $b$-metric Space. Turkish Journal of Analysis and Number Theory, 2, (1), (2014), 19-22.

[21] V. Ozturka, D. Turkoglub, Common fixed point theorems for mappings satisfying (E.A)property in bmetric spaces. J Nonlinear Sci Appl, 8, (2015), 1127-1133.

[22] J. R. Roshan, N. Shobkolaei, S. Sedghi and M. Abbas, Common fixed point of four maps in $b$-metric spaces. Hacettepe Journal of Mathematics and Statistics, 43, (4), (2014), 613-624.

[23] M. Sarwar, M. U. Rahman, Fixed point theorems for Ciric's and generalized contraction in $b$-metric spaces. International Journal of Analysis and Applications, 7, (1), (2015), 70-78.

[24] S. Xie, Y. Wang, L. Zhong, Some fixed point theorems in $b$-metric spaces, International Journal of Pure and Applied Mathematics, 110,(4), (2016), 571-580. 